\title{
Switchable Dual-Emissive DNA-Stabilized Silver Nanoclusters
}

Cerretani, Cecilia; Vosch, Tom

Published in:

ACS Omega

DOI:

$10.1021 /$ acsomega.9b00614

Publication date:

2019

Document version

Publisher's PDF, also known as Version of record

Document license:

CC BY-NC

Citation for published version (APA):

Cerretani, C., \& Vosch, T. (2019). Switchable Dual-Emissive DNA-Stabilized Silver Nanoclusters. ACS Omega, 4(4), 7895-7902. https://doi.org/10.1021/acsomega.9b00614 


\title{
Switchable Dual-Emissive DNA-Stabilized Silver Nanoclusters
}

\author{
Cecilia Cerretani and Tom Vosch*i) \\ Nano-Science Center/Department of Chemistry, University of Copenhagen. Universitetsparken 5, 2100 Copenhagen, Denmark
}

Supporting Information

ABSTRACT: We investigated an ss-DNA sequence that can stabilize a red- and a green-emissive silver nanocluster (DNA-AgNC). These two emitters can convert between each other in a reversible way. The change from red- to green-emitting DNA-AgNCs can be triggered by the addition of $\mathrm{H}_{2} \mathrm{O}_{2}$, while the opposite conversion can be achieved by the addition of $\mathrm{NaBH}_{4}$. Besides demonstrating the switching between red- and green-emissive DNA-AgNCs and determining the recoverability, we fully characterized the photophysical properties, such as steady-state emission, quantum yield, fluorescence lifetime, and anisotropy of the two emissive species. Understanding the mechanism behind the remarkable conversion between the two

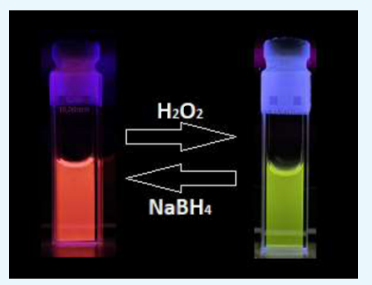
emitters could lead to the development of a new range of DNA-AgNC-based ratiometric sensors.

\section{INTRODUCTION}

DNA-templated silver nanoclusters (DNA-AgNCs) are a relatively new class of emitters formed by $2-30$ silver atoms embedded in one or multiple single-stranded DNA oligomers. $^{1-3}$ Thanks to their straightforward synthesis and tunability of excitation and emission wavelengths, ${ }^{4-6}$ DNAAgNCs have found several applications in sensing and fluorescence imaging. ${ }^{7-11}$ Among the DNA sequences that stabilize emissive AgNCs, some can produce one specific emitter, while others host a range of different emitters. Typical examples of DNA sequences that can stabilize multiple emitters are polycytosine (polyC) oligomers. ${ }^{12-14}$ The emission wavelength of the emitters enclosed in such sequences tends to blue-shift over time in ambient conditions. $^{12,13,15}$ If oxidation is the cause of the observed spectral blueshift, this could open up the possibility of developing DNA-AgNC-based redox-sensitive probes. Choi et al. have recently explored this concept for the detection of oxidizing species, like hypochlorite and reactive oxygen species (ROS), using DNA-AgNCs. ${ }^{14,16}$ In their experiments, ratiometric analysis of the emission in the presence of various oxidizing agents was performed. A further extension of this concept would be the development of reversible redoxsensitive ratiometric probes, which would be beneficial for many applications because the number of such probes available is currently limited. ${ }^{17,18} \mathrm{Li}$ et al. showed reversible switching between red- and green-emissive AgNCs stabilized in a DNA hydrogel. ${ }^{19}$ These AgNCs were applied to detect ROS and reactive nitrogen species (ROS/RNS) in living cells, thanks to their sensitivity to ${ }^{\circ} \mathrm{OH}$ radicals. Another example of conversion between differently colored AgNCs triggered by $\mathrm{H}_{2} \mathrm{O}_{2}$ and $\mathrm{NaBH}_{4}$ was provided by Anand et al., who used human serum albumin (HSA) as a scaffold to stabilize the AgNCs. ${ }^{20}$ HSA can stabilize a blue- and a red-emitting AgNC depending on the addition of $\mathrm{H}_{2} \mathrm{O}_{2}$ or $\mathrm{NaBH}_{4}$.

In this work, we investigated a DNA sequence that supports a switchable green- and red-emissive DNA-AgNC. The sequence of the 22-base DNA strand, 5'-TTC CCA CCC
ACC CCG GCC CGT T-3', was previously reported by Copp et al. ${ }^{21}$ Although originally described to stabilize a red-emitting DNA-AgNC that can be purified and isolated by HPLC, we noticed that prolonged storage led to a conversion of this red emitter into a green emitter (see Figure S1). This observation inspired us to study the conversion in more detail.

Our investigation shows that 5'-TTC CCA CCC ACC CCG GCC CGT T-3' can stabilize a red and a green emitter, and the switching between the two clusters can be triggered by the addition of $\mathrm{H}_{2} \mathrm{O}_{2}$ or $\mathrm{NaBH}_{4}$. Additionally, a number of nonfluorescent intermediate and "over-reduced" species are formed, limiting full reversibility between the two emitters. Understanding of the mechanistic details behind the conversion could lead to the development of ratiometric redox probes based on DNA-AgNCs. Besides investigating the conversion between the red- and the green-emissive DNAAgNCs, we fully characterized the photophysical properties of both emitters.

\section{EXPERIMENTAL SECTION}

Material and Methods. Synthesis. The synthesis of DNAAgNCs was performed using a one-pot method. First, hydrated ss-DNA (5'-TTC CCA CCC ACC CCG GCC CGT T-3', IDT) was mixed with $\mathrm{AgNO}_{3}$ (>99.998\%, Fluka Analytical) in a solution of $10 \mathrm{mM}$ ammonium acetate $\left(\mathrm{NH}_{4} \mathrm{OAc}\right)$ in nuclease-free water (IDT). After $15 \mathrm{~min}, \mathrm{NaBH}_{4}$ (99.99\%, Sigma-Aldrich) was added to reduce the silver cations. In the final solution, the concentration ratio of $[\mathrm{DNA}] /\left[\mathrm{AgNO}_{3}\right] /$ $\left[\mathrm{NaBH}_{4}\right]$ was $20 \mu \mathrm{M}: 200 \mu \mathrm{M}: 100 \mu \mathrm{M}$. The sample was stored in the fridge overnight and then upconcentrated using spin filtration (Amicon Ultra-2 Centrifugal Filter Unit with Ultracel-3 membrane) before injection in the HPLC system. After HPLC purification, the sample was solvent-exchanged by spin filtration into $10 \mathrm{mM} \mathrm{NH} \mathrm{NH}_{4} \mathrm{OAc} \mathrm{pH}=7$. The $\mathrm{NH}_{4} \mathrm{OAc}$

Received: March 5, 2019

Accepted: April 19, 2019

Published: April 30, 2019 
solution guarantees a good chemical stability of the DNAAgNCs over time. ${ }^{22}$

HPLC Purification. The HPLC purification was performed using a preparative HPLC system from Agilent Technologies with a Kinetex column $(5 \mu \mathrm{m}, 100 \AA$, $50 \times 4.6 \mathrm{~mm})$ with the C18 stationary phase. The HPLC instrument is equipped with absorption (Agilent Technologies 1100 series) and fluorescence (Agilent Technologies 1260 infinity) detectors. The mobile phase was a gradient mixture of $35 \mathrm{mM}$ triethylammonium acetate (TEAA) in methanol and water. The gradient was varied from 20 to $95 \%$ TEAA in methanol in 19 minutes. In the time range $2-17 \mathrm{~min}$, the gradient flow was linear: from 20 to $35 \%$ TEAA in methanol. The run was followed by $6 \mathrm{~min}$ of washing with 95\% TEAA in methanol. The flow rate was 1.3 $\mathrm{mL} / \mathrm{min}$. The purification was based on the absorbance signal at $570 \mathrm{~nm}$, that corresponds to the absorption of the redemissive DNA-AgNC.

Even though there are two main peaks in the $570 \mathrm{~nm}$ chromatogram (Figure S2A), the fraction that was collected was the one that eluted around $13 \mathrm{~min}$ (31\% TEAA in methanol). This is because the content of the green emitter is lower at this retention time.

Steady-State Absorption and Emission Spectroscopy. The absorption measurements were carried out on a Cary 300 UV-vis spectrophotometer (Agilent Technologies) and a Lambda1050 instrument from PerkinElmer using a deuterium lamp for ultraviolet radiation and a halogen lamp for visible and NIR.

Steady-state fluorescence measurements were performed using QuantaMaster400 from PTI/HORIBA with a xenon arc lamp as the excitation source. All fluorescence spectra were corrected for the wavelength dependency of the detector system.

Time-Correlated Single Photon Counting. Time-resolved fluorescence and anisotropy measurements were performed using the FluoTime300 instrument from PicoQuant with 470 $\mathrm{nm}$ (LDH-P-C-470) and $560 \mathrm{~nm}$ (LDH-D-TA-560) lasers as excitation sources for the green and the red emitter, respectively.

Acquisition and Analysis of Time-Resolved Emission Spectra Data. Time-resolved emission spectra (TRES) were acquired by increasing the emission monochromator in steps of $5 \mathrm{~nm}$, with an integration time of $30 \mathrm{~s}$ per decay in order to achieve at least 10000 counts in the maximum at the emission maximum. The analysis of time-resolved data was performed with Fluofit v.4.6 from PicoQuant. All decays were fitted globally with a triexponential reconvolution model including scattered light contribution and the IRF (instrument response function). The obtained TRES were corrected for the detector efficiency and transformed to wavenumber units by multiplying with the Jacobian factor $\left(\lambda=10^{7} / \nu^{2}\right){ }^{23}$ TRES were interpolated with a spline function using the built-in spaps MATLAB function with a tolerance of $10^{-10}$ (forcing the interpolated curve to go through the data points). The curve was interpolated using wavenumber steps equivalent to 0.01 $\mathrm{nm}$ wavelength steps. The emission maxima were taken as the maxima of the interpolated TRES. The average decay time $\langle\tau\rangle$ of every decay was calculated as the intensity-weighted average lifetime. The intensity-weighted lifetime $\left\langle\tau_{\omega}\right\rangle$ was calculated as the average of $\langle\tau\rangle$ over the emission spectra weighted by the steady-state intensity. ${ }^{13}$

Acquisition and Analysis of Time-Resolved Anisotropy Data. Time-resolved anisotropy measurements were carried out by exciting the sample with vertically polarized light and acquiring both vertically and horizontally polarized fluorescence intensity decays. The decays were fitted by Fluofit v.4.6 from PicoQuant. A triexponential and a monoexponential reconvolution model were used, respectively, for the lifetime and the rotational correlation time $(\theta)$, including the IRF. The Perrin equation ${ }^{24} \theta=\eta V / k_{\mathrm{B}} T$, where $\eta$ is the dynamic viscosity of the solvent, $V$ is the hydrodynamic volume of the species, and $k_{\mathrm{B}} T$ is the product between the Boltzmann constant and the absolute temperature, allowed us to calculate the hydrodynamic volume for both red and green emitters. In the Perrin model, the investigated species are assumed spherical for simplicity.

\section{RESULTS AND DISCUSSION}

After synthesis, the DNA-AgNCs were HPLC-purified (see Figure S2). The main fraction, that elutes around $13 \mathrm{~min}$, usually contains a large amount of red emitter and a minor content of green emitter. The red emitter is characterized by an absorption maximum at $573 \mathrm{~nm}$ and an emission maximum around $640 \mathrm{~nm}$, whereas the green emitter is identified by an absorption maximum at $493 \mathrm{~nm}$ and an emission maximum around $560 \mathrm{~nm}$ (see Figure S3 for excitation and emission spectra of the two emitters). Although it is possible to collect a fraction containing only the red emitter by optimizing the collection time, in this work, we used a fraction that also contains a minor amount of green emitter. The presence of the green-emitting DNA-AgNC is not an issue because we plan to switch back and forth between the two emitters. Moreover, storing a pure red emitter fraction for a few months in the fridge will lead also to the conversion of some of the red emitters to the green emitters (see Figure S1). In the next section, we will demonstrate the conversion of the red emitter to the green emitter by adding the oxidizing reagent $\mathrm{H}_{2} \mathrm{O}_{2}$, and the recovery of the red emitter to $\sim 60-80 \%$ of the original amount by addition of the reducing agent $\mathrm{NaBH}_{4}$.

Conversion Experiment. We started by preparing four equal solutions of HPLC-purified DNA-AgNCs (containing mainly the red emitter, see Figure S2) and we added $20 \mu \mathrm{L}$ of $\mathrm{H}_{2} \mathrm{O}_{2} 147 \mathrm{mM}(0.5 \% \mathrm{w} / \mathrm{V})$ to every cuvette, where the concentration of DNA was $2.8 \mu \mathrm{M}$ (see Figure 1).

Figure $2 \mathrm{~A}$ shows the conversion for cuvette 1 during the first day. The addition of $\mathrm{H}_{2} \mathrm{O}_{2}$ promotes the switching from red to green emitters as can be seen by the drop of the absorption

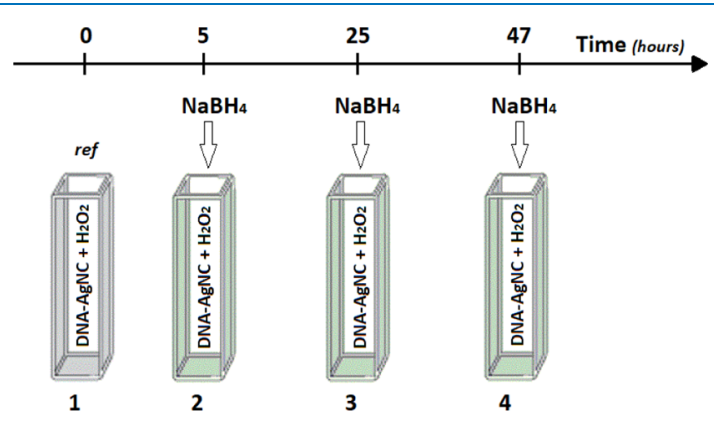

Figure 1. Scheme of the conversion experiment. At time zero, $20 \mu \mathrm{L}$ $\mathrm{H}_{2} \mathrm{O}_{2} 147 \mathrm{mM}$ was added to all four cuvettes $\left(V_{\text {tot }}=2 \mathrm{~mL}\right)$. No $\mathrm{NaBH}_{4}$ was added to cuvette 1 , hence this cuvette acted as the reference for the other cuvettes. Starting after $5 \mathrm{~h}, \mathrm{NaBH}_{4}$ was added to cuvette 2 , after $25 \mathrm{~h}$ to cuvette 3 , and after $47 \mathrm{~h}$ to cuvette 4 . See Figures S4-S6 for details on specific amounts and specific times. 


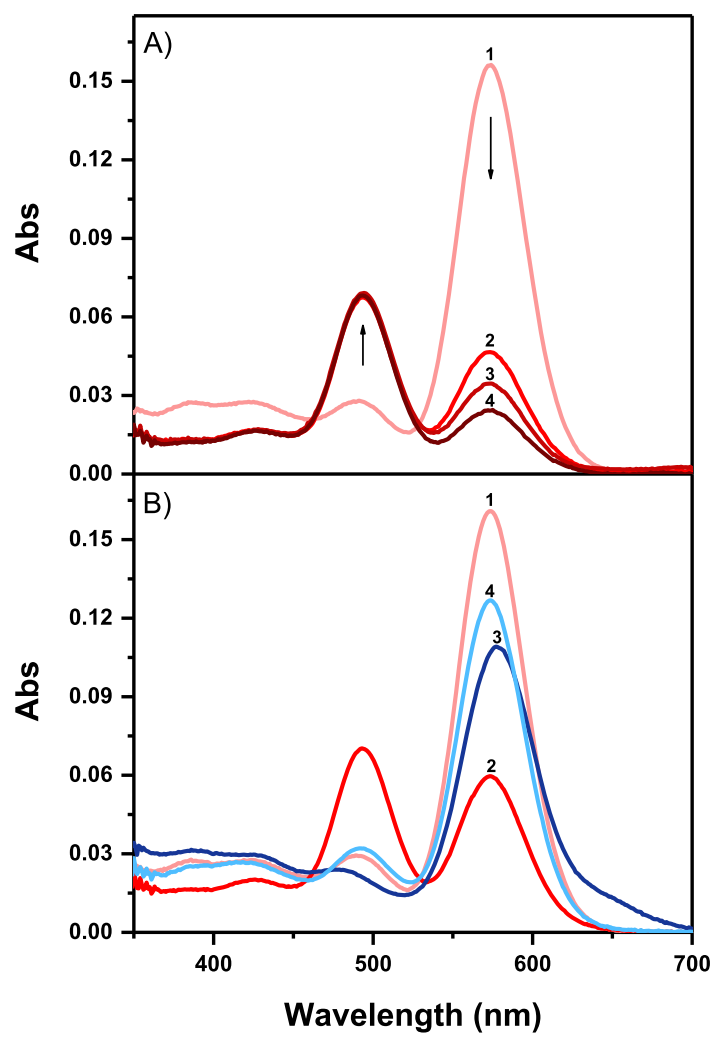

Figure 2. Absorption spectra of (A) cuvette 1 and (B) cuvette 2 on the first day of the 3-day measurement. (A) Spectrum 1 is the starting DNA-AgNC sample. Spectra 2, 3, and 4 correspond to the oxidized sample after 6, 8, and $10 \mathrm{~h}$, respectively. (B) Selected absorption spectra of some of the conversion steps for cuvette 2 . The light red spectrum 1 is the starting DNA-AgNC sample, while the dark red spectrum 2 is the sample after $5 \mathrm{~h}$. The dark blue 3 and light blue 4 spectra represent the sample (after $5 \mathrm{~h}$ ) right after the addition of 5 $\mu \mathrm{L} \mathrm{NaBH}{ }_{4} 1 \mathrm{mM}$ and $1 \mathrm{~h}$ later, respectively. For more spectra, see Figures S4-S6.

peak at $573 \mathrm{~nm}$ and the rise of the band at $493 \mathrm{~nm}$ over time. One point to note is that after $6 \mathrm{~h}$, the absorption of the green emitter reaches a constant value, while the red emitter keeps decreasing (see curves 1-4 in Figures 2A and S4 for additional spectra). In cuvettes 2,3 , and 4 , the same conversion is observed during the first $5 \mathrm{~h}$ (see Figure S4). The addition of 5 $\mu \mathrm{L}$ of fresh $\mathrm{NaBH}_{4} 1 \mathrm{mM}$ to the second cuvette after $5 \mathrm{~h}$ recovers the red emitter, as shown in Figure 2B. When measured immediately after the addition of $\mathrm{NaBH}_{4}$, a minor redshift of the absorption band at $573 \mathrm{~nm}$ and a longer wavelength tail are observed (see the dark blue curve in Figures $2 \mathrm{~B}$ and $\mathrm{S4}$ ). We attribute the red tail around $650 \mathrm{~nm}$ and the increased absorbance below $450 \mathrm{~nm}$ to an "overreduction". However, when the same solution is measured $1 \mathrm{~h}$ later, the spectrum shows the usual red emitter absorption peak (light blue curve in Figure 2B). An explanation could be that the remaining $\mathrm{H}_{2} \mathrm{O}_{2}$ in the solution removes the overreduced species and initiates again the conversion from red to green emitters (re-appearance of the peak at $493 \mathrm{~nm}$ ).

After the first addition of $\mathrm{NaBH}_{4}$ to cuvette 2, additional amounts of $5 \mu \mathrm{L} \mathrm{NaBH}_{4}(1 \mathrm{mM})$ were added every hour, for the next $4 \mathrm{~h}$. The additional $\mathrm{NaBH}_{4}$ improves the recoverability, but the effect seems to level out after several additions (see Figure 3C). On the second day, fresh $\mathrm{NaBH}_{4}$ was added to the second and third cuvettes, and on the third

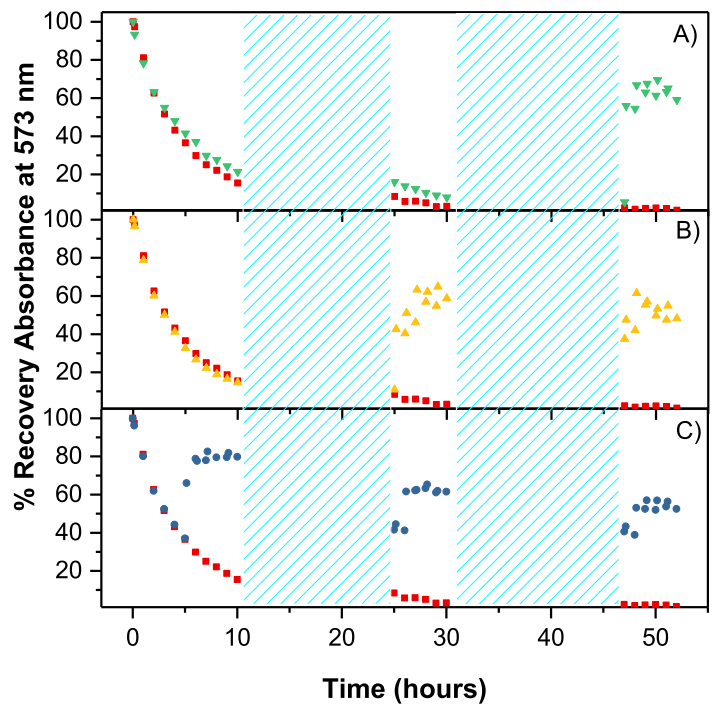

Figure 3. Percent recovery of the absorbance at $573 \mathrm{~nm}$ over time. The red scatter plot represents the absorbance drop of red emitters in cuvette 1. The blue (C), yellow (B), and green (A) symbols correspond to the absorbance changes in cuvettes 2,3 , and 4 , respectively.

day, the reducing agent was added to the second, third, and forth cuvettes. In between the experiments, all cuvettes were stored in the fridge (light blue dashed regions in Figure 3). All the absorption spectra of day 1,2 , and 3 are reported in Figures S4-S6 in the Supporting Information.

The results of the conversion experiment are summarized in Figure 3, which shows the absorbance variation of the red emitter in every cuvette throughout the experiment. The absorbance is expressed in percentage with respect to the initial value, in order to highlight the recoverability of the red emitter upon addition of $\mathrm{NaBH}_{4}$.

The red scatter plot refers to cuvette 1 that acts as a reference for all other cuvettes in the conversion process because no $\mathrm{NaBH}_{4}$ was added to it. The blue, yellow, and green symbols display the evolution of the absorbance of the red emitter upon addition of $\mathrm{NaBH}_{4}$ for cuvettes 2, 3, and 4, respectively. It is interesting to point out that the recovery of the red emitter increases with additional amounts of $\mathrm{NaBH}_{4}$ but levels out around $60-80 \%$ for all the cuvettes. Another aspect to highlight is that upon prolonged exposure to $\mathrm{H}_{2} \mathrm{O}_{2}$, the green emitter also starts to disappear over time (see, e.g., the absorption peak at $493 \mathrm{~nm}$ in Figures S4A, S5A, and S6A).

Based on the fact that the reversibility between the red and green emitters can be triggered by the addition of oxidizing $\left(\mathrm{H}_{2} \mathrm{O}_{2}\right)$ and reducing agents $\left(\mathrm{NaBH}_{4}\right)$, we propose that the origin of the difference between the red and green emitter is mainly linked to distinct degrees of oxidation of the AgNCs embedded in the DNA strand. However, until the mechanism of the conversion is understood, other possible explanations cannot be excluded. Conversion from red to green emitter can also be achieved by storage in the fridge at $4{ }^{\circ} \mathrm{C}$ as mentioned earlier (very slow conversion, see Figure S1) or irradiation at $365 \mathrm{~nm}$ by the handheld UV lamp (similar fast conversion as $\mathrm{H}_{2} \mathrm{O}_{2}$, see Figure S7).

Detailed inspection of the absorption spectra indicates that besides the prominent absorption features at 493 and $573 \mathrm{~nm}$ that can be assigned to the green and red emitters, respectively, other minor absorption characteristics are present. Initially and 
upon addition of $\mathrm{NaBH}_{4}$ to the green emitter, features at 390 $\mathrm{nm}$ and at $430 \mathrm{~nm}$ are present. Both peaks drop gradually when exposed to $\mathrm{H}_{2} \mathrm{O}_{2}$. We speculate that these and other absorption features are intermediate and "over-reduced" species because none of them show up in the excitation spectrum of the green and red emitter and are nonfluorescent (see Figures S3 and 6). This assumption could also explain why the red emitter does not fully recover to $100 \%$ because some DNA-AgNCs might still be present as intermediate or "over-reduced" species.

According to models proposed by Copp et al., ${ }^{3}$ Schultz et al., ${ }^{25}$ Petty et al., ${ }^{26-28}$ and Huard et al., ${ }^{29}$ DNA-AgNCs comprise a core/group of neutral $\mathrm{Ag}$ atoms surrounded by $\mathrm{Ag}^{+}$ cations. The number of neutral atoms defines the emission wavelength of the clusters, while the $\mathrm{Ag}^{+}$cations "glue" the core and the DNA bases together. Copp et al. demonstrated previously that green and red emissions tend to be linked to four and six neutral core $\mathrm{Ag}$ atoms, respectively. ${ }^{3}$

Based on mass spectrometry evidence, Copp et al. concluded that the red emitter used in this work contains six neutral $\mathrm{Ag}^{0}$ atoms and eight $\mathrm{Ag}^{+}$cations. ${ }^{21}$ Under the assumption that the change from the red to green emitter is due to oxidation, we can hypothesize that the green emitter contains four neutral $\mathrm{Ag}^{0}$ atoms. ${ }^{3}$ This means that two $\mathrm{Ag}^{0}$ atoms from the core of the original red emitter oxidize to $\mathrm{Ag}^{+}$. In this way, the overall number of silver atoms and cations bound to the DNA stays constant, but the electronic and fluorescent properties can shift in a step-wise manner depending on the number of neutral silver atoms. This mechanism can explain how a single oligonucleotide can stabilize different emitters. A scheme outlining our phenomenological model can be found in Figure 4. It summarizes the effect of $\mathrm{H}_{2} \mathrm{O}_{2}$ and $\mathrm{NaBH}_{4}$ on the

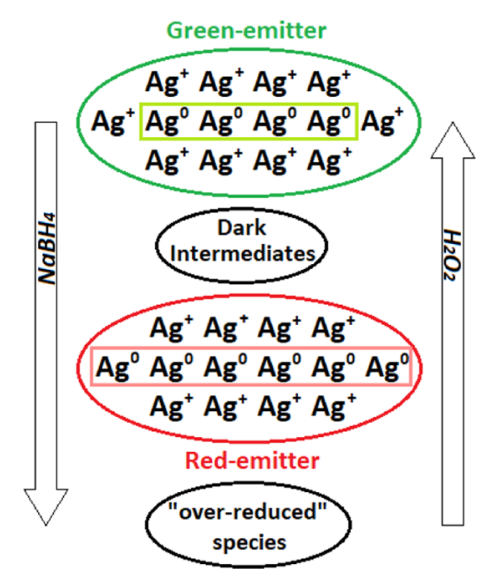

Figure 4. Schematic of the composition of red and green emitters, as well as the intermediate and "over-reduced" species. The number of $\mathrm{Ag}^{0}$ atoms in the core of dark intermediates and "over-reduced" species is unknown at this point. The dark intermediate species and "over-reduced" species are characterized by absorption features at $360,390,430 \mathrm{~nm}$, around $550 \mathrm{~nm}$, and a tail around $650 \mathrm{~nm}$

conversion between red and green emitters, as well as the presence of dark intermediates and "over-reduced" species. We would like to point out that these dark intermediates and "over-reduced" species are ground-state species and should not be confused with the microsecond-lived dark-excited states that the DNA-AgNCs can form. ${ }^{30,31}$ It is not unfeasible to imagine that some of the over-reduced species could be intermediates on the way to a further red-shifted emitter with more than $6 \mathrm{Ag}^{0}$ atoms. However, there is no indication that this particular DNA sequence supports a NIR emitter.

For simplicity, the structure proposed in Figure 4 is just a cartoon. Recent findings have shown that the AgNC is not necessarily organized as one continuous spherical or rod-like unit, but it can contain regions of clustered $\mathrm{Ag}^{0}$ atoms and regions where silver ions form a wire, promoting base pair interactions and forcing the DNA in a specific conformation. ${ }^{29}$

To challenge our phenomenological model, we also performed experiments that exposed the red emitter first to additional $\mathrm{NaBH}_{4}$, followed by the addition of $\mathrm{H}_{2} \mathrm{O}_{2}$. The addition of $5 \mu \mathrm{L} \mathrm{NaBH} \mathrm{N}_{4}(1 \mathrm{mM})$ to freshly purified clusters produced features in the absorption spectrum that match well with the previously described "over-reduced" species. As shown in Figure 5A, the minor amount of green emitter at

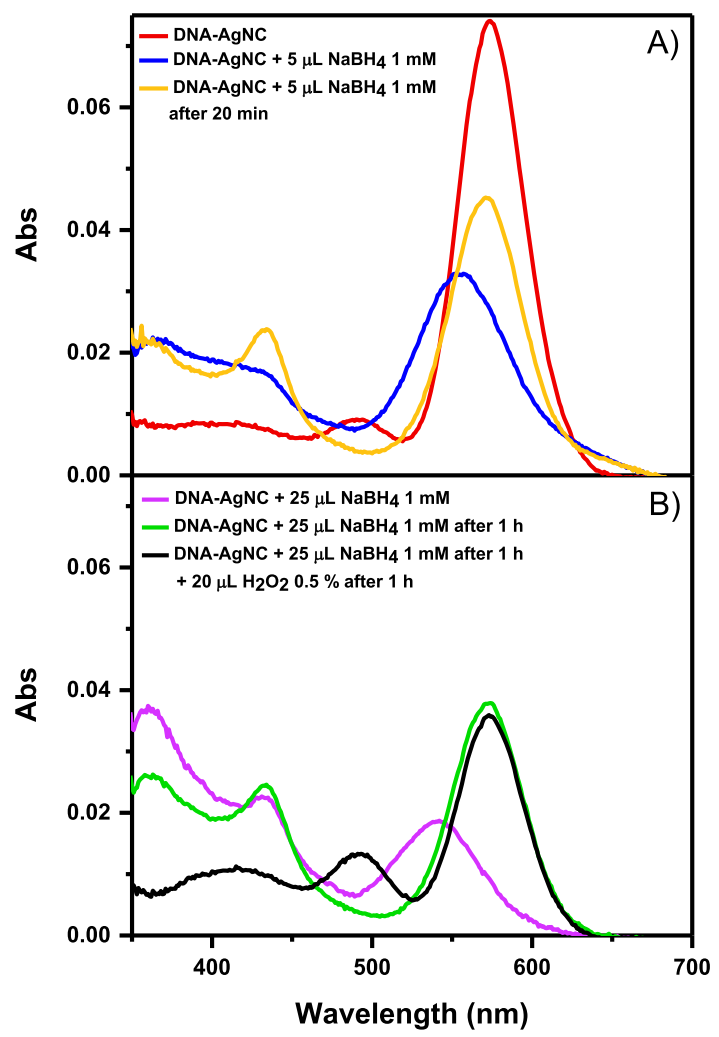

Figure 5. Selected absorption spectra of purified DNA-AgNCs upon the addition of (A) $5 \mu \mathrm{L} \mathrm{NaBH}_{4} 1 \mathrm{mM}$ and (B) $25 \mu \mathrm{L} \mathrm{NaBH}_{4} 1 \mathrm{mM}$ and further addition of $20 \mu \mathrm{L} \mathrm{H}_{2} \mathrm{O}_{2} 147 \mathrm{mM}(0.5 \% \mathrm{w} / \mathrm{V})$. (For more spectra, see Figure S8). The volumes mentioned in the legend represent the total volume added.

$493 \mathrm{~nm}$ disappears, while a red shoulder at $650 \mathrm{~nm}$ rises, similar to Figure 2B. At the same time, two pronounced features around 360 and $430 \mathrm{~nm}$ appear. Instead of the original peak from the red emitter at $573 \mathrm{~nm}$, a blue-shifted peak at 551 $\mathrm{nm}$ is now present. It is interesting to point out that after 20 min, the red emitter (peak at $573 \mathrm{~nm}$ ) was partially restored. Further additions up to $25 \mu \mathrm{L} \mathrm{NaBH}_{4}(1 \mathrm{mM})$ to the solution (Figure 5B, see also Figure S8) enhance again the "overreduced" features (peaks at 360 and $430 \mathrm{~nm}$ ). Intriguingly, the absorption band close to the position of the red emitter is now even further blue-shifted to $542 \mathrm{~nm}$. Waiting for $1 \mathrm{~h}$ restores again the red emitter peak around $573 \mathrm{~nm}$. To confirm that the treatment with $\mathrm{NaBH}_{4}$ does not compromise the conversion capabilities to the green emitter, $\mathrm{H}_{2} \mathrm{O}_{2}$ was added after $1 \mathrm{~h}$ (see 
Figure 5B). The addition of the oxidizing agent fully removed the "over-reduced" species and the green emitter starts to reappear (peak at $493 \mathrm{~nm}$ ).

Based on our observations, we conclude that the oxidizing and reducing agents $\left(\mathrm{H}_{2} \mathrm{O}_{2}\right.$ and $\left.\mathrm{NaBH}_{4}\right)$ can change the features observed in the absorption spectrum of the DNAAgNC. In fact, besides the two main emitters, a number of intermediate and "over-reduced" species can be produced, of which the nature is not determined at this point. The intermediates and "over-reduced" species can also explain the limited reversibility of circa $60-80 \%$ observed in Figure 3. Because the intermediates and "over-reduced" species are nonemissive, we will focus in the next section only on the fluorescence properties of the red and green emitter.

Photophysical Characterization of the Red and Green Emitter. The main spectroscopic features of the green and red emitter are summarized in Table 1.

Table 1. Steady-State and Time-Resolved Photophysical Properties of Green and Red Emitters

$\begin{array}{lll} & \text { green emitter }^{a} & \text { red emitter } \\ \lambda_{\text {abs }}(\max ) & 493 \mathrm{~nm} & 573 \mathrm{~nm} \\ \lambda_{\text {em }}(\max ) & 560 \mathrm{~nm} & 640 \mathrm{~nm} \\ \left\langle\tau_{\mathrm{w}}\right\rangle^{c} & 1.75 \mathrm{~ns} & 2.95 \mathrm{~ns} \\ \text { TRES shift }^{d} & 450.63 \mathrm{~cm}^{-1} & 226.11 \mathrm{~cm}^{-1} \\ \text { QY }^{e} & 0.25 & 0.87\end{array}$

${ }^{a_{T}}$ The steady-state emission and absorption spectra for the green emitter were acquired on red-emissive DNA-AgNCs exposed to $20 \mu \mathrm{L}$ $\mathrm{H}_{2} \mathrm{O}_{2} 147 \mathrm{mM}$ for $5 \mathrm{~h}$, while the fluorescence decays were measured on red-emissive DNA-AgNCs exposed to $20 \mu \mathrm{L} \mathrm{H}_{2} \mathrm{O}_{2} 147 \mathrm{mM}$ for 30 h. ${ }^{b}$ Every measurement reported for the red emitter was carried out on the pure fraction in $10 \mathrm{mM} \mathrm{NH}_{4} \mathrm{OAc}$. ${ }^{c}$ The average decay time is weighted by the intensity over the whole emission range. ${ }^{d}$ The emission maximum shift is determined from the IRF-limited resolution $(\sim 150 \mathrm{ps})$ to $10 \mathrm{~ns} .{ }^{e}$ Fluorescence quantum yield at 25 ${ }^{\circ} \mathrm{C}$. Fluorescein in $\mathrm{NaOH} 0.1 \mathrm{M}$ was used as a reference for the green emitter, while cresyl violet in pure ethanol was the reference dye for the red emitter. ${ }^{32}$ The quantum yield of the green emitter was determined by measuring the naturally oxidized nanoclusters after 1.5 month storage in the fridge.

Figure 6 shows the emission vs excitation 2D plots of the two emitters. Figure $6 \mathrm{~A}$ is the freshly HPLC-purified fraction containing mainly the red emitter and a very small amount of

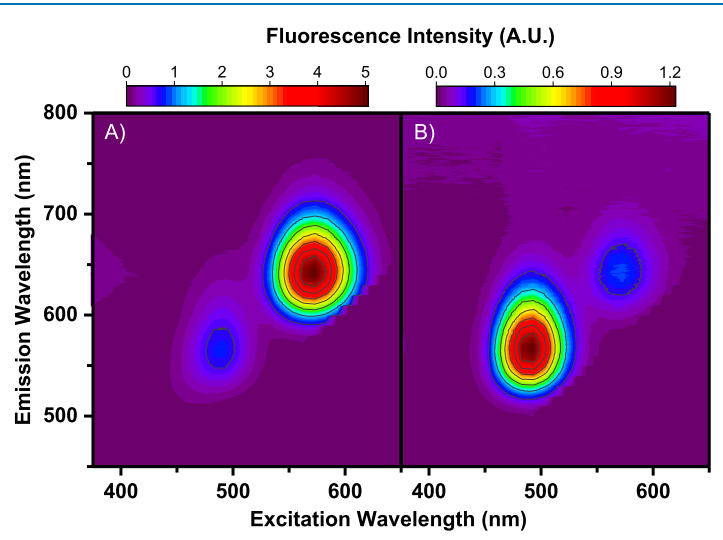

Figure 6. Emission vs excitation $2 \mathrm{D}$ plots of (A) freshly purified DNA-AgNCs and (B) DNA-AgNCs $+20 \mu \mathrm{L} \mathrm{H}_{2} \mathrm{O}_{2} 147 \mathrm{mM}$ after 25 h (cuvette 3). green emitter, as described above. Figure $6 \mathrm{~B}$ displays the data from cuvette $3,25 \mathrm{~h}$ after the addition of $20 \mu \mathrm{L} \mathrm{H}_{2} \mathrm{O}_{2} 147 \mathrm{mM}$. The fluorescence quantum yield of the green emitter was determined to be 0.25 , while red emitter's quantum yield was 0.87 at room temperature. After characterizing the steady-state properties of the two emitting DNA-AgNCs, time-correlated single photon counting (TCSPC) measurements were performed at room temperature. Similar to our previous findings, ${ }^{22,33,34}$ a triexponential model was needed to satisfactorily fit the globally linked fluorescence decay curves for both red and green emitters. TRES were constructed from TCSPC data in the range between the IRF limited resolution $(\sim 150 \mathrm{ps})$ and $10 \mathrm{~ns}$. The normalized TRES for both green and red emitters, shown in Figure 7A,C, reveal a continuous redshift of the emission spectrum during this time period. This has been previously described and explained by a slow spectral relaxation. ${ }^{33,35,36}$ It is relevant to point out that this relaxation is only a small part of the overall relaxation and that the
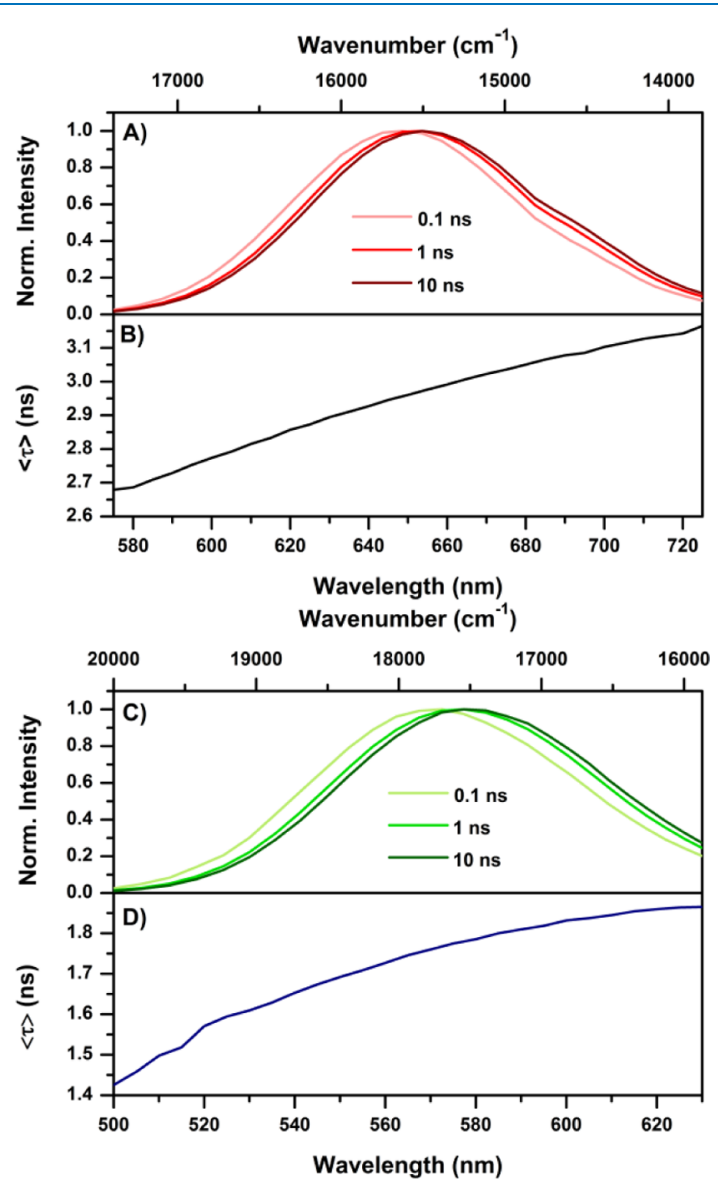

Figure 7. (A) TRES and (B) average lifetime as a function of the emission wavelength of the red emitter, exciting at $560 \mathrm{~nm}$. The measurements were acquired from a fraction containing only the redemissive DNA-AgNCs. The corresponding fluorescence intensity decays used to construct TRES and to calculate the average lifetime are reported in Figure S9. (C) TRES and (D) average decay time as a function of the emission wavelength of the green emitter, exciting at $470 \mathrm{~nm}$. The measurements were acquired from a sample of redemissive DNA-AgNCs that was exposed to $20 \mu \mathrm{L} \mathrm{H}_{2} \mathrm{O}_{2} 147 \mathrm{mM}$ for $30 \mathrm{~h}$. The oxidizing agent converted most of the red emitters into green-emissive DNA-AgNCs. The corresponding fluorescence intensity decays used to construct TRES and to estimate the average decay time are reported in Figure S10. 
majority of the spectral relaxation, responsible for the total Stokes shift, happens on an ultrafast timescale $(<1 \mathrm{ps}) .^{37-40}$ This slow spectral relaxation, on the time scale of the fluorescence decay time, causes the decay to become multiexponential at fixed emission wavelengths and leads to an increase of the average lifetime as a function of the emission wavelength (Figure $7 \mathrm{~B}, \mathrm{D}) .^{24}$

The average decay time of the green emitter is $1.75 \mathrm{~ns}$, much shorter than the fluorescence lifetime of the red emitter that equals to $2.95 \mathrm{~ns}$. The spectral relaxation in the time window accessible by our TCSPC equipment is larger for the green emitter $\left(450.63 \mathrm{~cm}^{-1}\right)$ than for the red emitter $\left(226.11 \mathrm{~cm}^{-1}\right)$. In order to rule out large DNA conformational changes or multiple strand interactions as the cause of the conversion between the red and green emitters, we determined the hydrodynamic volume of both emitters by measuring the timeresolved anisotropy at various temperatures: 5,15 , and $25{ }^{\circ} \mathrm{C}$. It was previously shown by Petty et al. that the hybridization of DNA-AgNC with complementary DNA strands can convert certain AgNCs into other ones (more specifically dark species into emissive species). ${ }^{41-45}$ The interaction between two or more DNA strands would likely have a measurable impact on the hydrodynamic volume.

Fitting the anisotropy decay curves (Figures S11 and S12) yielded rotational correlation times $(\theta)$ that allowed us to calculate the hydrodynamic volumes $(V)$ of the red and the green emitter to be 12.48 and $12.96 \mathrm{~nm}^{3}$, respectively (see Figure S13). These values support the conclusion that the two emissive DNA-AgNCs are similar in size and that the conversion is not due to changes in the number of DNA strands stabilizing the two emitters, but, for example, due to a change in the oxidation state of some of the $\mathrm{Ag}$ atoms. However, minor DNA conformation changes during the conversion between the red and green emitters cannot be excluded.

\section{CONCLUSIONS}

In summary, we demonstrated that the DNA strand $5^{\prime}$-TTC CCA CCC ACC CCG GCC CGT T-3' can stabilize a red and a green emitter and the conversion between them is possible. The switching from red to green emitter can be triggered by the addition of $\mathrm{H}_{2} \mathrm{O}_{2}$, while the opposite conversion is caused by the addition of $\mathrm{NaBH}_{4}$. Moreover, a number of dark intermediate and "over-reduced" species were observed. The presence of these species seems to limit the conversion between red- and green-emissive DNA-AgNCs to about 60$80 \%$. We speculate that this switching is caused by an oxidation/reduction of some silver atoms. Furthermore, we characterized the photophysical properties of the two emitters and showed that they have very similar hydrodynamic volumes, indirectly supporting the oxidation/reduction model. Because of the limited number of redox-sensitive ratiometric fluorophores, further studies of this and other switchable DNA-AgNCs could result in the development of new probes. Additionally, our work might also contribute in the understanding of the optical properties of AgNCs stabilized in other matrices, for example, zeolites. ${ }^{46-48}$

\section{ASSOCIATED CONTENT}

\section{S Supporting Information}

The Supporting Information is available free of charge on the ACS Publications website at DOI: 10.1021/acsomega.9b00614.
Additional absorption, emission and excitation spectra. HPLC chromatograms, fluorescence intensity decays, and rotational correlation time information (PDF)

\section{AUTHOR INFORMATION}

\section{Corresponding Author}

*E-mail: tom@chem.ku.dk.

\section{ORCID $\odot$}

Tom Vosch: 0000-0001-5435-2181

\section{Author Contributions}

The manuscript was written through contributions of all the authors. All the authors have given approval to the final version of the manuscript.

\section{Notes}

The authors declare no competing financial interest.

\section{ACKNOWLEDGMENTS}

We gratefully acknowledge financial support from the "Center for Synthetic Biology" at Copenhagen University funded by the UNIK research initiative of the Danish Ministry of Science, Technology and Innovation (grant 09-065274), the University of Copenhagen's Excellence Programme for Interdisciplinary Research (bioSYNergy), the Villum Foundation (VKR023115), and the Carlsberg Foundation (CF14-0388, CF17-0470).

\section{REFERENCES}

(1) Petty, J. T.; Zheng, J.; Hud, N. V.; Dickson, R. M. DNAtemplated Ag nanocluster formation. J. Am. Chem. Soc. 2004, 126, 5207-5212.

(2) Schultz, D.; Gwinn, E. G. Silver atom and strand numbers in fluorescent and dark Ag:DNAs. Chem. Commun. 2012, 48, 57485750 .

(3) Copp, S. M.; Schultz, D.; Swasey, S.; Pavlovich, J.; Debord, M.; Chiu, A.; Olsson, K.; Gwinn, E. Magic Numbers in DNA-Stabilized Fluorescent Silver Clusters Lead to Magic Colors. J. Phys. Chem. Lett. 2014, 5, 959-963.

(4) Richards, C. I.; Choi, S.; Hsiang, J.-C.; Antoku, Y.; Vosch, T.; Bongiorno, A.; Tzeng, Y.-L.; Dickson, R. M. Oligonucleotidestabilized Ag nanocluster fluorophores. J. Am. Chem. Soc. 2008, 130, 5038-5039.

(5) Swasey, S. M.; Copp, S. M.; Nicholson, H. C.; Gorovits, A.; Bogdanov, P.; Gwinn, E. G. High throughput near infrared screening discovers DNA-templated silver clusters with peak fluorescence beyond $950 \mathrm{~nm}$. Nanoscale 2018, 10, 19701-19705.

(6) Copp, S. M.; Gorovits, A.; Swasey, S. M.; Gudibandi, S.; Bogdanov, P.; Gwinn, E. G. Fluorescence color by data-driven design of genomic silver clusters. ACS Nano 2018, 12, 8240-8247.

(7) Guo, W.; Yuan, J.; Dong, Q.; Wang, E. Highly SequenceDependent Formation of Fluorescent Silver Nanoclusters in Hybridized DNA Duplexes for Single Nucleotide Mutation Identification. J. Am. Chem. Soc. 2010, 132, 932-934.

(8) Guo, W.; Yuan, J.; Wang, E. Oligonucleotide-stabilized Ag nanoclusters as novel fluorescence probes for the highly selective and sensitive detection of the $\mathrm{Hg} 2+$ ion. Chem. Commun. 2009, 33953397.

(9) Shah, P.; Rørvig-Lund, A.; Chaabane, S. B.; Thulstrup, P. W.; Kjaergaard, H. G.; Fron, E.; Hofkens, J.; Yang, S. W.; Vosch, T. Design Aspects of Bright Red Emissive Silver Nanoclusters/DNA Probes for MicroRNA Detection. ACS Nano 2012, 6, 8803-8814.

(10) Richards, C. I.; Hsiang, J.-C.; Senapati, D.; Patel, S.; Yu, J.; Vosch, T.; Dickson, R. M. Optically Modulated Fluorophores for Selective Fluorescence Signal Recovery. J. Am. Chem. Soc. 2009, 131, 4619-4621. 
(11) Krause, S.; Carro-Temboury, M. R.; Cerretani, C.; Vosch, T. Anti-Stokes fluorescence microscopy using direct and indirect dark state formation. Chem. Commun. 2018, 54, 4569-4572.

(12) Ritchie, C. M.; Johnsen, K. R.; Kiser, J. R.; Antoku, Y.; Dickson, R. M.; Petty, J. T. Ag Nanocluster Formation Using a Cytosine Oligonucleotide Template. J. Phys. Chem. C 2007, 111, 175-181.

(13) Temboury, M. R. C.; Paolucci, V.; Hooley, E. N.; Latterini, L.; Vosch, T. Probing DNA-stabilized fluorescent silver nanocluster spectral heterogeneity by time-correlated single photon counting. Analyst 2016, 141, 123-130.

(14) Choi, S.; Park, S.; Lee, K.; Yu, J. Oxidant-resistant imaging and ratiometric luminescence detection by selective oxidation of silver nanodots. Chem. Commun. 2013, 49, 10908-10910.

(15) Sharma, J.; Yeh, H.-C.; Yoo, H.; Werner, J. H.; Martinez, J. S. A complementary palette of fluorescent silver nanoclusters. Chem. Commun. 2010, 46, 3280-3282.

(16) Park, S.; Choi, S.; Yu, J. DNA-encapsulated silver nanodots as ratiometric luminescent probes for hypochlorite detection. Nanoscale Res. Lett. 2014, 9, 129.

(17) Liu, Y.; Liu, S.; Wang, Y. TEMPO-based Redox-sensitive Fluorescent Probes and Their Applications to Evaluating Intracellular Redox Status in Living Cells. Chem. Lett. 2009, 38, 588-589.

(18) Lou, Z.; Li, P.; Han, K. Redox-Responsive Fluorescent Probes with Different Design Strategies. Acc. Chem. Res. 2015, 48, 13581368

(19) Li, J.; Yu, J.; Huang, Y.; Zhao, H.; Tian, L. Highly Stable and Multiemissive Silver Nanoclusters Synthesized in Situ in a DNA Hydrogel and Their Application for Hydroxyl Radical Sensing. ACS Appl. Mater. Interfaces 2018, 10, 26075-26083.

(20) Anand, U.; Ghosh, S.; Mukherjee, S. Toggling Between Blueand Red-Emitting Fluorescent Silver Nanoclusters. J. Phys. Chem. Lett. 2012, 3, 3605-3609.

(21) Copp, S. M.; Schultz, D.; Swasey, S. M.; Faris, A.; Gwinn, E. G. Cluster Plasmonics: Dielectric and Shape Effects on DNA-Stabilized Silver Clusters. Nano Lett. 2016, 16, 3594-3599.

(22) Bogh, S. A.; Carro-Temboury, M. R.; Cerretani, C.; Swasey, S. M.; Copp, S. M.; Gwinn, E. G.; Vosch, T. Unusually large Stokes shift for a near-infrared emitting DNA-stabilized silver nanocluster. Methods Appl. Fluoresc. 2018, 6, 024004.

(23) Mooney, J.; Kambhampati, P. Get the Basics Right: Jacobian Conversion of Wavelength and Energy Scales for Quantitative Analysis of Emission Spectra. J. Phys. Chem. Lett. 2013, 4, 3316-3318.

(24) Lakowicz, J. R. Principles of Fluorescence Spectroscopy, 3rd ed.; Springer, 2006.

(25) Schultz, D.; Gardner, K.; Oemrawsingh, S. S. R.; Markešević, N.; Olsson, K.; Debord, M.; Bouwmeester, D.; Gwinn, E. Evidence for Rod-Shaped DNA-Stabilized Silver Nanocluster Emitters. Adv. Mater. 2013, 25, 2797-2803.

(26) Petty, J. T.; Sergev, O. O.; Ganguly, M.; Rankine, I. J.; Chevrier, D. M.; Zhang, P. A Segregated, Partially Oxidized, and Compact Ag10 Cluster within an Encapsulating DNA Host. J. Am. Chem. Soc. 2016, 138, 3469-3477.

(27) Petty, J. T.; Ganguly, M.; Rankine, I. J.; Chevrier, D. M.; Zhang, P. A DNA-Encapsulated and Fluorescent Ag106+ Cluster with a Distinct Metal-Like Core. J. Phys. Chem. C 2017, 121, 14936-14945.

(28) Petty, J. T.; Ganguly, M.; Rankine, I. J.; Baucum, E. J.; Gillan, M. J.; Eddy, L. E.; Léon, J. C.; Müller, J. Repeated and Folded DNA Sequences and Their Modular Ag106+ Cluster. J. Phys. Chem. C 2018, 122, 4670-4680.

(29) Huard, D. J. E.; Demissie, A.; Kim, D.; Lewis, D.; Dickson, R. M.; Petty, J. T.; Lieberman, R. L. Atomic Structure of a Fluorescent Ag8 Cluster Templated by a Multistranded DNA Scaffold. J. Am. Chem. Soc. 2018, DOI: 10.1021 /jacs.8b 12203.

(30) Vosch, T.; Antoku, Y.; Hsiang, J.-C.; Richards, C. I.; Gonzalez, J. I.; Dickson, R. M. Strongly emissive individual DNA-encapsulated Ag nanoclusters as single-molecule fluorophores. Proc. Natl. Acad. Sci. U.S.A. 2007, 104, 12616-12621.
(31) Volkov, I. L.; Serdobintsev, P. Y.; Kononov, A. I. DNAStabilized Silver Nanoclusters with High Yield of Dark State. J. Phys. Chem. C 2013, 117, 24079-24083.

(32) Brouwer, A. M. Standards for photoluminescence quantum yield measurements in solution (IUPAC Technical Report). Pure Appl. Chem. 2011, 83, 2213-2228.

(33) Cerretani, C.; Carro-Temboury, M. R.; Krause, S.; Bogh, S. A.; Vosch, T. Temperature dependent excited state relaxation of a red emitting DNA-templated silver nanocluster. Chem. Commun. 2017, 53, 12556-12559.

(34) Bogh, S. A.; Cerretani, C.; Kacenauskaite, L.; Carro-Temboury, M. R.; Vosch, T. Excited-State Relaxation and Förster Resonance Energy Transfer in an Organic Fluorophore/Silver Nanocluster Dyad. ACS Omega 2017, 2, 4657-4664.

(35) Hsu, H.-C.; Ho, M.-C.; Wang, K.-H.; Hsu, Y.-F.; Chang, C.-W. DNA stabilized silver nanoclusters as the fluorescent probe for studying the structural fluctuations and the solvation dynamics of human telomeric DNA. New J. Chem. 2015, 39, 2140-2145.

(36) Wang, K.-H.; Chang, C.-W. The spectral relaxation dynamics and the molecular crowding effect of silver nanoclusters synthesized in the polymer scaffold. Phys. Chem. Chem. Phys. 2015, 17, 2314023146.

(37) Patel, S. A.; Cozzuol, M.; Hales, J. M.; Richards, C. I.; Sartin, M.; Hsiang, J.-C.; Vosch, T.; Perry, J. W.; Dickson, R. M. Electron Transfer-Induced Blinking in Ag Nanodot Fluorescence. J. Phys. Chem. C 2009, 113, 20264-20270.

(38) Yau, S. H.; Abeyasinghe, N.; Orr, M.; Upton, L.; Varnavski, O.; Werner, J. H.; Yeh, H.-C.; Sharma, J.; Shreve, A. P.; Martinez, J. S.; Goodson III, T. Bright two-photon emission and ultra-fast relaxation dynamics in a DNA-templated nanocluster investigated by ultra-fast spectroscopy. Nanoscale 2012, 4, 4247-4254.

(39) Thyrhaug, E.; Bogh, S. A.; Carro-Temboury, M. R.; Madsen, C. S.; Vosch, T.; Zigmantas, D. Ultrafast coherence transfer in DNAtemplated silver nanoclusters. Nat. Commun. 2017, 8, 15577.

(40) Reveguk, Z.; Lysenko, R.; Ramazanov, R.; Kononov, A. Ultrafast fluorescence dynamics of DNA-based silver clusters. Phys. Chem. Chem. Phys. 2018, 20, 28205-28210.

(41) Petty, J. T.; Story, S. P.; Juarez, S.; Votto, S. S.; Herbst, A. G.; Degtyareva, N. N.; Sengupta, B. Optical Sensing by Transforming Chromophoric Silver Clusters in DNA Nanoreactors. Anal. Chem. 2012, 84, 356-364.

(42) Petty, J. T.; Giri, B.; Miller, I. C.; Nicholson, D. A.; Sergev, O. O.; Banks, T. M.; Story, S. P. Silver Clusters as Both Chromophoric Reporters and DNA Ligands. Anal. Chem. 2013, 85, 2183-2190.

(43) Petty, J. T.; Sergev, O. O.; Nicholson, D. A.; Goodwin, P. M.; Giri, B.; McMullan, D. R. A Silver Cluster-DNA Equilibrium. Anal. Chem. 2013, 85, 9868-9876.

(44) Petty, J. T.; Nicholson, D. A.; Sergev, O. O.; Graham, S. K. Near-Infrared Silver Cluster Optically Signaling Oligonucleotide Hybridization and Assembling Two DNA Hosts. Anal. Chem. 2014, 86, 9220-9228.

(45) Petty, J. T.; Sergev, O. O.; Kantor, A. G.; Rankine, I. J.; Ganguly, M.; David, F. D.; Wheeler, S. K.; Wheeler, J. F. Ten-Atom Silver Cluster Signaling and Tempering DNA Hybridization. Anal. Chem. 2015, 87, 5302-5309.

(46) De Cremer, G.; Coutiño-Gonzalez, E.; Roeffaers, M. B. J.; Moens, B.; Ollevier, J.; Van der Auweraer, M.; Schoonheydt, R.; Jacobs, P. A.; De Schryver, F. C.; Hofkens, J.; De Vos, D. E.; Sels, B. F.; Vosch, T. Characterization of Fluorescence in Heat-Treated SilverExchanged Zeolites. J. Am. Chem. Soc. 2009, 131, 3049-3056.

(47) Grandjean, D.; Coutiño-Gonzalez, E.; Cuong, N. T.; Fron, E.; Baekelant, W.; Aghakhani, S.; Schlexer, P.; D’Acapito, F.; Banerjee, D.; Roeffaers, M. B. J.; Nguyen, M. T.; Hofkens, J.; Lievens, P. Origin of the bright photoluminescence of few-atom silver clusters confined in LTA zeolites. Science 2018, 361, 686-690.

(48) Aghakhani, S.; Grandjean, D.; Baekelant, W.; CoutiñoGonzalez, E.; Fron, E.; Kvashnina, K.; Roeffaers, M. B. J.; Hofkens, J.; Sels, B. F.; Lievens, P. Atomic scale reversible opto-structural 
switching of few atom luminescent silver clusters confined in LTA zeolites. Nanoscale 2018, 10, 11467-11476. 